\title{
Tag attachment success can be temperature dependent: a case study of the chub mackerel Scomber japonicus
}

\author{
Tohya Yasuda ${ }^{*}$, Naoki Nagano², Hajime Kitano ${ }^{2}$, Hirofumi Ohga ${ }^{3}$, Takeshi Sakai ${ }^{1}$, Seiji Ohshimo ${ }^{1,4}$ \\ and Michiya Matsuyama ${ }^{3}$
}

\begin{abstract}
Background: Electronic tags are increasingly used in the studies of fish, but the attachment of electronic tags may affect their behaviour and physiology. While a number of studies have shown effects of electronic tags on fish health and behaviour, few have examined the effects of thermal conditions on the consequences of electronic tagging. In the present study, we conducted two laboratory experiments under two different water temperatures ( $22.5 \pm 1.5$ and $12.7 \pm 1.8^{\circ} \mathrm{C}$ ) to evaluate the growth and survival of commercially reared chub mackerel Scomber japonicus tagged with a dummy electronic tag.

Results: The presence of the tag, but not the surgical operation itself, significantly decreased fish survival rate under warm conditions, whereas high survival rates (ca. $96 \%$ ) were observed for both tagged and untagged fish under cold conditions. No difference in growth rate was found between the tagged and untagged fish under cold conditions, but tagged fish grew more poorly than untagged fish under warm conditions.
\end{abstract}

Conclusions: Our result showed that water temperature clearly affects the impact of tagging on the health of commercially reared chub mackerel.

Keywords: Biologging, Biotelemetry, Behaviour, Tagging, Migration, Small pelagic fish, Water temperature

\section{Background}

Electronic tags are increasingly used in fish behavioural and physiological studies $[1,2]$. However, the behaviour and physiology of fish are affected not only by the attachment of electronic tags but also by environmental variables such as water temperature [3, 4]. Because the immune systems of fish may respond strongly at high temperatures, leading to more rapid healing $[5,6]$, water temperatures could be an important factor affecting consequences of electronic tagging [e.g., 7-9]. While a number of studies have shown effects of electronic tags on fish health and behaviour, few have examined how these effects are altered by thermal conditions [3, 4]. This is especially true for marine fishes [4].

\footnotetext{
*Correspondence: ytohya@affrc.go.jp

1 Seikai National Fisheries Research Institute, Fisheries Research Agency,

1551-8 Taira-machi, Nagasaki 851-2213, Japan

Full list of author information is available at the end of the article
}

In the present study, we examined the effects of thermal conditions on the survival and growth of tagged chub mackerel, Scomber japonicus. S. japonicus is a small pelagic fish with a wide distribution in temperate and subtropical zones. Electronic tagging studies of chub mackerel are needed to understand their migration patterns in relation to environmental factors [10]. However, the efficacy of electronic tags in studies remains untested not only for chub mackerel but also for other small pelagic fishes [4]. Indeed, there may be strong constraints on the use of electronic tags in these fishes, as the fishes are sensitive to handling. Therefore, assessing the effects of electronic tags on these fish is an important first step in recording the behaviours of small pelagic fish. The present study conducted two laboratory experiments under different water temperatures. The first experiment (warm condition) was conducted from September to November, at mean water temperatures of $22.5 \pm 1.5^{\circ} \mathrm{C}$.

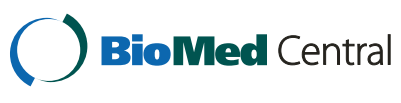

(c) 2015 Yasuda et al. This article is distributed under the terms of the Creative Commons Attribution 4.0 International License (http://creativecommons.org/licenses/by/4.0/), which permits unrestricted use, distribution, and reproduction in any medium, provided you give appropriate credit to the original author(s) and the source, provide a link to the Creative Commons license, and indicate if changes were made. The Creative Commons Public Domain Dedication waiver (http://creativecommons.org/ publicdomain/zero/1.0/) applies to the data made available in this article, unless otherwise stated. 
The second experiment (cold condition) was conducted from December to January at mean water temperatures of $12.7 \pm 1.8^{\circ} \mathrm{C}$.

\section{Results}

Under warm conditions, we found that the survival rate of the tagged fish was much lower than that of the untagged fish (Fig. 1a). A Cox regression model revealed that the presence of a tag significantly affected the survival rate of the fish (Table 1). However, there was no significant effect of the surgical operation itself, the duration of tag deployment, or the duration of anaesthesia on fish survival rate. Although the effect of fish body mass was
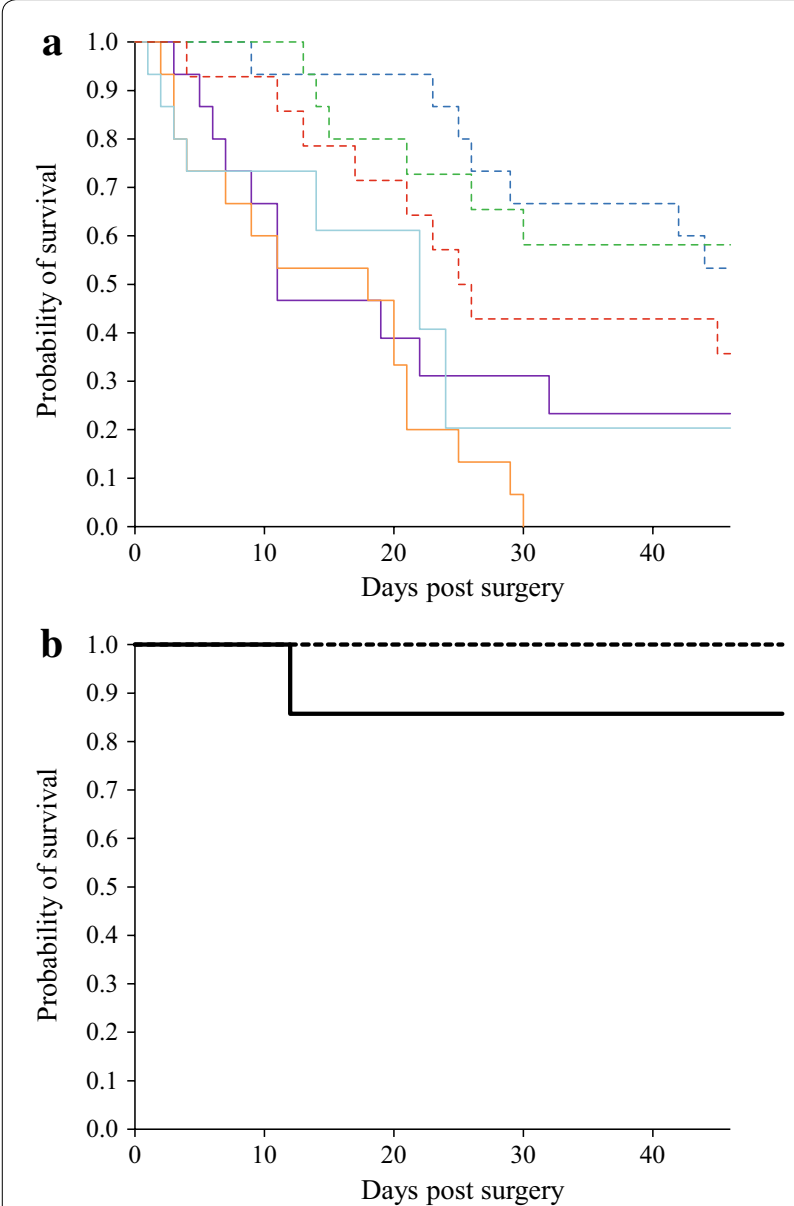

Fig. 1 Kaplan-Meier survival curves for adult chub mackerel. a Warm condition experiment. Solid and dashed lines indicate survival curves of the tagged and untagged groups, respectively. Different colours represent different groups: Untagged (b/ue), Implant-sham (green), External-sham (red), Implantation-A (purple), External-1 (orange), and External-2 (sky blue). b Cold condition experiment. Dashed lines (always 1.0) indicate survival curves of Implantation-B, ImplantationC, and Untagged groups. Solid line represents Implantation-A group statistically significant in the model, the magnitude of this effect was less than one-fortieth of that of the presence of a tag. No significant difference in survival was observed between groups of fish tagged using different tagging methods (log-rank test, $\chi^{2}=2.3467, d f=2$, $P=0.3093$ ).

In the cold condition, both the tagged and untagged fish experienced a high rate of survival (Fig. 1b). With the exception of one fish that died 12 days later, all fish survived until the end of the experiment, and no significant difference in survival was observed among groups $\left(x^{2}=3.5714, d f=3, P=0.3116\right)$. The effects of tag coating and tag size were also not statistically significant.

To determine whether water temperature alters the effect of tag presence on fish survival rate, two Cox regression models (one with and one without water temperature as a factor) were compared (Table 2). An analysis of model $\mathrm{A}$, which included water temperature, indicated that both tag presence and water temperature affected fish survival. However, tag presence was not significant in the analysis of model B, which did not include water temperature. Removing water temperature from the model greatly affected the parameter estimate for the effect of tag presence.

The growth rate of experimental fish was different between the two experiments. Under warm conditions, body mass tended to increase in the untagged fish, whereas it clearly decreased in the tagged fish (Table 3 ). Under cold conditions, there was an increase in fish body mass in all treatments. No difference in growth rate was observed between any treatment groups at cold temperatures $\left(\chi^{2}=2.3099, d f=3, P=0.5106\right)$.

No tags were shed from any fish in the two experiments, with the exception of the External-2 group. Fortyseven percent of the tags of the External-2 group were shed during the experiment due to breakage of the muscle near the hole on the body wall on which the attachment was made using a stainless wire. Mean duration of the tag retention was $15.4 \pm 12.7$ days (range 8-46 days).

Our observations of deceased fish under warm conditions revealed typical features of infectious diseases common to fish. An additional graphic file shows these in more detail (see Additional file 1: Figure S1).

\section{Discussion}

Water temperature is the most commonly studied environmental variable in evaluating the effects of environmental correlates on fish health after tagging [4]. In hybrid striped bass Morone saxatilis $\times$ Morone chrysops held at high $\left(22-29{ }^{\circ} \mathrm{C}\right)$ and low $\left(12-18{ }^{\circ} \mathrm{C}\right)$ temperatures, survival rate was lower at high temperatures, with tagged fish exhibiting significantly lower survival than untagged fish [7]. This result might be because of possible interactions between 
Table 1 Results of Cox regression analysis showing effects of the tagging components on survival of the chub mackerel in the experiment under warm conditions

\begin{tabular}{|c|c|c|c|c|c|c|}
\hline \multirow{2}{*}{$\begin{array}{l}\text { Tagging component } \\
\text { Tag presence (Implantation, External, Untagged) }\end{array}$} & \multicolumn{2}{|c|}{ Parameter estimates } & \multirow{2}{*}{$\begin{array}{l}\text { SE } \\
0.511\end{array}$} & \multirow{2}{*}{$\begin{array}{l}d f \\
2\end{array}$} & \multirow{2}{*}{$\begin{array}{l}x^{2} \\
11.536\end{array}$} & \multirow{2}{*}{$\begin{array}{l}\boldsymbol{P} \\
0.003^{*}\end{array}$} \\
\hline & Implantation & 0.745 & & & & \\
\hline & External & 0.280 & 0.666 & & & \\
\hline \multirow[t]{2}{*}{ Surgical operation (ventrotomy, pitting, non-surgery) } & Ventrotomy & -0.010 & 0.950 & 2 & 0.960 & 0.619 \\
\hline & Pitting & 0.252 & 0.507 & & & \\
\hline Duration of tag deployments (s) & & -0.006 & 0.007 & 1 & 0.784 & 0.376 \\
\hline Duration of anaesthesia (s) & & 0.002 & 0.002 & 1 & 1.015 & 0.314 \\
\hline Body mass (g) & & -0.005 & 0.003 & 1 & 4.004 & $0.045^{*}$ \\
\hline
\end{tabular}

* Statistically significant $P<0.05$

Table 2 Comparison of Cox regression models that include and do not include the effect of water temperature

\begin{tabular}{|c|c|c|c|c|c|c|}
\hline Tagging component & Parameter estimates & & SE & $d f$ & $x^{2}$ & $P$ \\
\hline \multicolumn{7}{|l|}{ Model A } \\
\hline Tag presence (Implantation or Untagged) & Implantation & 1.148 & 0.421 & 1 & 8.277 & $0.004^{*}$ \\
\hline Water temperature condition (warm or cold) & Warm & 2.044 & 0.723 & 1 & 10.550 & $0.001^{*}$ \\
\hline Duration of tag deployments (s) & & -0.007 & 0.006 & 1 & 1.781 & 0.182 \\
\hline Duration of anaesthesia (s) & & 0.003 & 0.003 & 1 & 1.544 & 0.214 \\
\hline Body mass (g) & & -0.003 & 0.004 & 1 & 0.632 & 0.426 \\
\hline \multicolumn{7}{|l|}{ Model B } \\
\hline Tag presence (Implantation or untagged) & Implantation & 0.304 & 0.291 & 1 & 1.128 & 0.288 \\
\hline Duration of tag deployments (s) & & 0.004 & 0.004 & 1 & 1.332 & 0.248 \\
\hline Duration of anaesthesia (s) & & -0.004 & 0.002 & 1 & 7.509 & $0.006^{*}$ \\
\hline Body mass (g) & & -0.005 & 0.004 & 1 & 1.451 & 0.228 \\
\hline
\end{tabular}

* Statistically significant $P<0.05$

the presence of a tag and water temperatures. Similar results were observed in Pacific lamprey Lampetra tridentata held at 8 and $19-23{ }^{\circ} \mathrm{C}$ [8] and bluegills Lepomis macrochirus held at 6 and $20{ }^{\circ} \mathrm{C}$ [9]. The present study revealed that ambient water temperature significantly affected the survival of tagged chub mackerel. Under warm conditions $\left(22.5 \pm 1.5^{\circ} \mathrm{C}\right)$, the presence of a tag significantly decreased the survival of chub mackerel. Under cold conditions $\left(12.7 \pm 1.8^{\circ} \mathrm{C}\right)$, the presence of the tag had no effect. This decrease in fish survival and growth at warm temperatures matches results of the previous studies. For Chinook salmon Oncorhynchus tshawytscha, however, Ammann et al. [12] reported relatively high survival at lower temperatures $\left(<12.5^{\circ} \mathrm{C}\right)$ compared to the survival rate seen in the studies conducted by Brown et al. [13] at warmer temperatures $\left(13-16^{\circ} \mathrm{C}\right)$. Temperature ranges in these studies seem to be lower than those of the studies described above. In contrast, Frost et al. [14] reported that no Chinook salmon held at $12-21{ }^{\circ} \mathrm{C}\left(\mathrm{ca} .17^{\circ} \mathrm{C}\right)$ died as a result of tagging. Survival of rainbow trout Oncorhynchus mykiss held at 10,15 , and $20^{\circ} \mathrm{C}$ was also not related to temperature [15]. This variability suggests the responses of tagged fish to water temperatures may vary among species and/or families. It is also possible that the differences in the experimental condition explain the disagreements among these studies. Further research should examine how temperature effects vary among species and how water temperature interacts with other factors.

Water temperatures in the two experiments were within the thermal tolerance thresholds of chub mackerel. According to Shaefer [16], the lower and upper temperature limits for lethality in chub mackerel are 6 and $29^{\circ} \mathrm{C}$, respectively, and important changes in behaviour (i.e., a reduced rate of feeding) occur when the water temperature drops below $10{ }^{\circ} \mathrm{C}$ or exceeds $27^{\circ} \mathrm{C}[16,17]$. The water temperature in our experiments did not reach these thresholds. Actual habitat temperature of chub mackerel in the East China Sea seems to be $15-22{ }^{\circ} \mathrm{C}$ during the main fishing season [10]. These temperatures are similar to those in our experiments. One possible reason for the low survival rate in our experiment is that the chemical, physical, biological characteristics of water clearly vary between the laboratory and open seas. Unfortunately, we had no data to clarify this hypothesis, although we have confirmed that the water quality in the laboratory was appropriate for chub mackerel breeding. The other reason is that there are likely additional factors that interact with water temperature and affect the growth and survival of tagged chub mackerel. 
Table 3 Mean \pm SD of body mass of chub mackerel immediately and 46 or 50 days post-surgery, and the associated specific growth rate

\begin{tabular}{|c|c|c|c|c|c|}
\hline \multirow[t]{2}{*}{ Experimental group } & \multirow[t]{2}{*}{$n$} & \multicolumn{2}{|l|}{ Days } & \multirow{2}{*}{$\begin{array}{l}\text { Specific growth } \\
\text { rate }(\%)\end{array}$} & \multirow{2}{*}{$\begin{array}{l}\text { Final survival } \\
\text { rate (\%) }\end{array}$} \\
\hline & & 0 & $46(50)$ & & \\
\hline \multicolumn{6}{|l|}{ Warm condition } \\
\hline \multirow[t]{2}{*}{ Implantation-A } & 2 & 475 & 468 & -0.03 & 23 \\
\hline & & 441 & 409 & -0.16 & \\
\hline External-1 & 0 & - & - & - & 0 \\
\hline External-2 & 1 & 411 & 314 & -0.58 & 20 \\
\hline Untagged & 8 & $482 \pm 81$ & $503 \pm 84$ & $0.10 \pm 0.22$ & 53 \\
\hline Implant-sham & 8 & $425 \pm 44$ & $447 \pm 68$ & $0.09 \pm 0.10$ & 58 \\
\hline External-sham & 5 & $476 \pm 84$ & $446 \pm 39$ & $-0.12 \pm 0.41$ & 36 \\
\hline \multicolumn{6}{|l|}{ Cold condition } \\
\hline Implantation-A & 6 & $474 \pm 31$ & $523 \pm 58$ & $0.18 \pm 0.11$ & 86 \\
\hline Implantation-B & 7 & $485 \pm 40$ & $547 \pm 55$ & $0.27 \pm 0.09$ & 100 \\
\hline Implantation-C & 8 & $510 \pm 72$ & $586 \pm 93$ & $0.24 \pm 0.07$ & 100 \\
\hline Untagged & 10 & $509 \pm 71$ & $579 \pm 81$ & $0.26 \pm 0.12$ & 100 \\
\hline
\end{tabular}

Infectious disease could contribute to the temperature sensitivity of tagged fish. Although we could not identify a specific source of disease, our visual observations of the deceased fish revealed typical features of common infectious diseases. Tag deployment may be a stress trigger, which may in turn cause outbreaks of infectious diseases [18]. Generally, fish reared at low temperature have lower immune responses [6], but at sufficiently cold temperatures it may be too cold for bacteria to multiply and cause acute disease [19]. Conversely, when healthy fish are reared at high temperature, a rapid increase in bacterial growth may overwhelm the faster response of the immune system [6]. Previous studies reported that significant irritation, infection, and mortality occurred when water temperature increased $[7,8]$. These results agree with those of the present study. Possibly, the regulatory pathway of immune responses might be perturbed in stressed (i.e., tagged) fish, and may make them more susceptible to infection. Although much remains unknown about the effects of water temperature on the health of tagged fish, it can at least be recommended that tags be attached at lower temperatures $[4,9]$.

Our results raise the question of whether high survival rates in tagged fish persist when water temperature increases during a change of season. Previous studies have shown that physiological stress levels return to normal within few days after tagging $[20,21]$, suggesting that these negative effects have a short duration. Although they are later compensated for, ameliorating these effects is one of the most important challenges for field tagging researchers [22].
Previous studies have shown that the induction and recovery times for anaesthesia are temperature dependent: anaesthesia is reached rapidly at warmer temperatures $[2,3]$. The duration of anaesthesia in the present study was comparable with other previous studies [e.g., 12], and no significant effect of anaesthesia was observed in S. japonicus.

We found clear differences in survival rates for the untagged groups between the warm and cold conditions (Fig. 1a, b). The untagged groups did not receive electronic tags but had PIT tags inserted into their muscle. This suggests that thermal conditions affect research performance of not only electronic tagging but also conventional tagging [8]. In the East China Sea, releaserecapture studies using conventional tags were conducted during the 1960s and 1970s, and tagged chub mackerel was released during all seasons [23]. These studies found a large difference in recovery rates for the tags (range 0.39-16.43\%). Mean recapture rate from 1967 to 1973 in summer (0.53\%, July-September) was lower than in autumn (7.72\%, October-December), winter (1.22\%, January-March) and spring (7.86 \%, AprilJune) [23]. Thermal conditions at the time of capture and tagging may affect subsequent recovery rates.

Tag shedding has been reported in a number of studies $[7-9,12-15]$. It may occur due to failure of the wound closure or some form of active expulsion on the part of the fish (e.g., transabdominal) [3, 4]. This study found no effect of water temperatures on tag retention for internal tagging methods in chub mackerel. No tags were shed from fish in the External-1 treatment, in which the tag 
was externally attached on the body using two plastic cable ties (see "Methods"). However, high tag shedding rate was observed in the External-2 treatment, in which the tag was connected using a stainless steel wire to fish and was towed behind the animal. One possible reason of the high tag shedding rate for the External-2 group is that resistive force derived from the tag may be concentrated on one part of the body.

This study conducted internal and external tagging methods. There was a difference in the duration of anaesthesia and the duration of tag attachments between the two methods (Table 4). Although we did not investigate swimming behaviour of fish in this study, these tagging methods might influence swimming performance and might be problematic in some environments [2]. Under warm conditions, we could not find any significant difference in survival rate between external and internal tagging methods, at least in the short term. Although a high survival rate of internally tagged fish was achieved at cold temperatures over the long term, future studies must confirm whether externally tagged fish remain similarly healthy under low temperature conditions [24, 25].

\section{Conclusions}

Water temperature clearly appears to act as a significant factor in the health of reared chub mackerel following electronic tagging. To minimise mortality among tagged fish, it is recommended to tag chub mackerel during the winter, when temperature is $<20{ }^{\circ} \mathrm{C}$. However, it is still unknown how water temperature interacts with other factors that affect the health of fish after tagging. In particular, further studies must address how water temperature effects vary among species or between reared and wild fish.

\section{Methods}

\section{General experimental procedures}

This study used 3-year-old commercially reared chub mackerel (Table 4). Mean body mass of experimental fish was $459 \pm 64 \mathrm{~g}$. The fish were caught by commercial purse seine fisheries in the coastal area around Kyushu, Japan when they were 0 -year-old fish, and were grown to maturity in a net cage. We carefully checked fish conditions prior to the experiments and used only healthy fish in the experiments.

The fish were anaesthetized with 2-phenoxyethanol (200-275 ppm solution), measured for fork length (cm) and body mass (g), and were held on the platform for the tag attachment. Seawater was circulated through the mouth of the fish with a water pump to aid in respiration during tag attachment. To identify all fish, we inserted a Passive Integrated Transponder (PIT) tag (BIO12B.01, BIOMARK Inc., Idaho, USA) into muscular tissue near the dorsal fin before applying the experimental treatment.

Experiments were conducted in a round tank $\sim 5 \mathrm{~m}$ diameter and $\sim 1 \mathrm{~m}$ in depth (i.e. $\sim 20 \mathrm{t}$ of water). The tank was exposed to ambient light and temperature (i.e., light and temperature were not regulated). The experimental system was confirmed to be appropriate for small pelagic fishes, including chub mackerel, in previous studies [e.g. 26]. During the experiments, we observed fish each day and fed dried pellets to the fish two or three times a day. During feeding, if diseased or moribund fish were found, they were caught, identified, and their fork length and body mass were measured. Subsequently, necropsies were conducted on these fish.

Due to a technical difficulty, we could not measure the body mass of 12 fish (seven from the ImplantationA group and five from the Implantation- $C$ group) at the

Table 4 Summary of data from experimental fish

\begin{tabular}{|c|c|c|c|c|c|}
\hline Experimental group & Fork length $(\mathrm{cm})$ & Body mass (g) & $\begin{array}{l}\text { Duration of } \\
\text { anaesthesia (s) }\end{array}$ & $\begin{array}{l}\text { Duration of tag } \\
\text { deployments (s) }\end{array}$ & $n$ \\
\hline \multicolumn{6}{|l|}{ Warm condition } \\
\hline Implantation-A & $31.7 \pm 1.2$ & $428 \pm 56$ & $293 \pm 61$ & $190 \pm 28$ & 15 \\
\hline External-1 & $32.1 \pm 0.9$ & $442 \pm 62$ & $393 \pm 155$ & $99 \pm 15$ & 15 \\
\hline External-2 & $31.9 \pm 1.2$ & $432 \pm 53$ & $323 \pm 62$ & $144 \pm 24$ & 15 \\
\hline Untagged $^{a}$ & $32.3 \pm 1.2$ & $486 \pm 66$ & $202 \pm 56$ & $b$ & 15 \\
\hline Implant-sham ${ }^{a}$ & $31.7 \pm 1.0$ & $426 \pm 46$ & $465 \pm 87$ & $167 \pm 28$ & 15 \\
\hline External-shama & $31.7 \pm 0.7$ & $459 \pm 59$ & $223 \pm 63$ & $\mathrm{~b}$ & 15 \\
\hline \multicolumn{6}{|l|}{ Cold condition } \\
\hline Implantation-A & $32.0 \pm 0.6$ & $475 \pm 41$ & $581 \pm 94$ & $170 \pm 12$ & 7 \\
\hline Implantation-B & $32.5 \pm 1.2$ & $485 \pm 40$ & $625 \pm 121$ & $190 \pm 21$ & 7 \\
\hline Implantation-C & $32.6 \pm 1.3$ & $510 \pm 72$ & $479 \pm 137$ & $169 \pm 15$ & 8 \\
\hline Untagged ${ }^{a}$ & $32.7 \pm 1.1$ & $509 \pm 71$ & $515 \pm 84$ & $\mathrm{~b}$ & 10 \\
\hline
\end{tabular}

a There was no tag deployed

b Durations were not scored as they were very short 
beginning of the experiment at the cold temperature. Body mass $(\mathrm{g})$ of these fish was therefore estimated by the power function of fork length $(\mathrm{cm})$ from other individuals in the same lot [Body mass $=0.0062 \times$ Fork length $\left.{ }^{3.2446}, R^{2}=0.7264, n=59, P<0.0001\right]$.

\section{Experiment at warm temperature}

This experiment was conducted from 30 September to 15 November 2013 (46 days). Water temperature at the start of the Experiment I was $\sim 24{ }^{\circ} \mathrm{C}$ and subsequently dropped to $\sim 19^{\circ} \mathrm{C}$. Changes in the daily water temperature were $0.30 \pm 0.06{ }^{\circ} \mathrm{C}(n=44)$.

Five archival tags and 40 dummy tags were used. LAT2800 (LOTEK Wireless Inc., Ontario, Canada), a relatively small tag, was used in this study. Few case studies of small scombrids have been carried out, and none of them specify an optimal size for tags. Because the LAT2800 is formed by mixing an epoxy resin and an amine-based epoxy hardener, the dummy tags were prepared using similar materials. All tags were $11 \mathrm{~mm}$ in diameter and $38 \mathrm{~mm}$ in length, and weighed $6.1 \pm 0.2 \mathrm{~g}$ in air $(n=45)$. The mean ratio of tag mass to fish body mass was $1.4 \pm 0.2 \%(n=45)$.

There were three tagged groups (Implantation-A, External-1, and External-2) and three untagged groups (Untagged, Implant-sham, and External-sham) with 15 fish in each group in the experiment. In the ImplantationA group, a $\sim 20 \mathrm{~mm}$ incision was made through the skin and muscle of the lower abdominal region of the fish with a scalpel, and a sterile tag was implanted into the peritoneal cavity. The incision was sutured with a round needle with a circular cross section (17 $\mathrm{mm}$ in length) and two stitches of a thread made from absorbable polyglycolic acid (Opepolyx N, Alfresa Co., Ltd., Tokyo, Japan). The incision was then sealed with an $\alpha$-cyanoacrylate-based quick-setting adhesive (Aron Alpha, Toagosei Co. Ltd., Tokyo Japan). In the External-1 group, we pitted two tiny holes $(<2 \mathrm{~mm}$ in diameter) near the dorsal fin using stainless steel needles, and the tag was fixed using two plastic cable ties $(<2 \mathrm{~mm}$ in width) through the holes. This method is commonly used in field studies of marine fish and allows long-term monitoring over months [27-29]. In the External-2 group, we made one tiny hole near the dorsal fin and the tag was towed using a silicon-coated stainless steel wire (1.5 $\mathrm{mm}$ in diameter).

We did not conduct any treatment in the Untagged group (i.e., we only inserted the PIT tag). The Implantsham and External-sham groups were used to examine the effects of the surgical operation itself. In the Implantsham group, the surgical operation was similar to that in the Implantation-A group, but no tag was implanted into the peritoneal cavity. In the External-sham group, we made one 2-mm hole near the dorsal fin, but neither the tag and plastic cable nor the stainless steel wire was attached.

\section{Experiment at cold temperature}

This experiment was conducted from 4 December 2013 to 23 January 2014 (50 days) and began with water temperature at $\sim 15{ }^{\circ} \mathrm{C}$, which subsequently fell to $\sim 10{ }^{\circ} \mathrm{C}$. Changes in the daily water temperature were $0.47 \pm 0.05{ }^{\circ} \mathrm{C}(n=49)$. No significant difference in the rate of change in the daily water temperature was noted between the warm and cold conditions ( $t$ test, $t=1.6296$, $d f=91, P=0.1066$ ).

Because low survival rates were observed in the External-1 and External-2 groups under warm-temperature conditions, external attachment groups were not included in this experiment. This experiment included three treatment groups (Implantation-A, Implantation$B$, Implantation-C) and one untagged group (Untagged). In the Implantation-A group, tags were identical to those used at warm temperatures. In the Implantation$B$ group, the tags were wrapped in paraffin film (Parafilm, Pechiney Plastic Packaging, Menasha, WI, USA), which might have some benefits in terms of biological compatibility (Y. Makiguchi, personal communication). In the Implantation- $C$ group, tags that were half the length and weight of standard tags were used, in order to reduce drag. The small tags were also wrapped in paraffin film. The mean ratios of tag mass to fish body mass were $1.32 \pm 0.08 \%$ for the Implantation-A group $(n=7)$, $1.29 \pm 0.10 \%$ for the Implantation-B group $(n=8)$, and $0.67 \pm 0.08 \%$ for the Implantation- $C(n=7)$ group. To reduce the possible number of fish lost, the sample size of each group was reduced in comparison to sample sizes in the warm-water experiment.

\section{Statistical analysis}

Specific Growth Rate (SGR) was calculated using the following equation: SGR $=\left(\ln M_{1}-\ln M_{2}\right) / \Delta d \times 100$ where $M_{1}$ and $M_{2}$ are body mass at the start and the end of the experiment, and $\Delta d$ is the number of days in the experiment.

The survival rate of each group was estimated using the Kaplan-Meier method. Data from cases in which a tag was expelled from an individual, or in which an individual survived until the end of each experiment, were treated as censored data. Differences in survival among groups were examined using the log-rank test. The Cox regression model (proportional hazards analysis) with a likelihood ratio test was fitted to determine which components of tagging affected fish survival. To determine whether water temperature alters the effect of tag deployment on fish survival, two Cox regression models (one with and one without temperature as a factor) were 
compared [11]. To fit these models, we used the data of the Implantation-A groups at both temperatures and the untagged groups at both temperatures, because no other variables (i.e., tag size, tag coating, surgery type, etc.) in these groups changed between the warm-condition experiment and the cold-condition experiment.

The cutoff for statistical significance was set at $\alpha=0.05$ for all statistical analyses. In cases where multiple comparisons were performed, a Bonferroni correction was used to keep the overall probability of a Type I error at $\alpha=0.05$.

\section{Additional file}

Additional file 1: Figure S1. Observation of experimental fish. Description of data: (a) Experimental fish at the end of the warm condition experiment. Note that the fish indicated by white arrows had dark body colours. (b) A deceased individual in the Implantation-A group in the warm condition. Abrasions on the body surface are indicated by white arrows. (c) A deceased individual in the Implantation group in the warm condition. Note the bleeding around the eye. (d) A cut from surgery on a deceased individual in the Implantation group in the warm condition. (e) A dummy tag in the peritoneal cavity of a normal individual in the Implantation group. (f) Tagged and untagged fish in the experiment in the cold condition.

\section{Authors' contributions}

TY, SO and MM coordinated the experiments. TY, NN, HK, HO, and TS designed and conducted the experiments. TY analysed data and wrote the manuscript. All authors read and approved the final manuscript.

\section{Author details}

1 Seikai National Fisheries Research Institute, Fisheries Research Agency, 1551-8 Taira-machi, Nagasaki 851-2213, Japan. ${ }^{2}$ Faculty of Agriculture, Fisheries Research Institute of Karatsu, Kyushu University, 59-2 Oka, Karatsu, Saga 847-0132, Japan. ${ }^{3}$ Laboratory of Marine Biology, Faculty of Agriculture, Kyushu University, Fukuoka 812-8581, Japan. ${ }^{4}$ Present Address: National Research Institute of Far Seas Fisheries, Shimizu, Shizuoka 424-8633, Japan.

\section{Acknowledgements}

We sincerely thank the staff of the Laboratory of Marine Biology, Kyushu University, for help with these experiments. We also thank H. Mitamura, M. Fukuwaka, and K. Yoseda for their constructive comments on the early draft of the manuscript. The present study was partly supported by JSPS KAKENHI Grant Number 15K18736.

\section{Competing interests}

The authors declare that they have no competing interests.

\section{Ethical statement}

This study was conducted according to the Guidelines for Animal Experimentation of the Seikai National Fisheries Research Institute, Fisheries Research Agency, Japan (No. 2013001)

Received: 24 April 2015 Accepted: 1 October 2015

Published online: 26 October 2015

\section{References}

1. Cooke SJ, Hinch SG, Wikelski M, Andrew ED, Wolcott TG, Butler PJ. Biotelemetry: a mechanistic approach to ecology. Trends Ecol Evol. 2004;19:334-43.
2. Bridger CJ, Booth RK. The effects of biotelemetry transmitter presence and attachment procedures on fish physiology and behavior. Rev Fish Sci. 2003;11:13-34.

3. Jepsen N, Koed A, Thorstad EB, Baras E. Surgical implantation of telemetry transmitters in fish: how much have we learned? Hydrobiologia. 2002;483:239-48.

4. Cooke SJ, Woodley CM, Eppard MB, Brown RS, Nielsen JL. Advancing the surgical implantation of electronic tags in fish: a gap analysis and research agenda based on a review of trends in intracoelomic tagging effects studies. Rev Fish Biol Fish. 2011;21:127-51.

5. Anderson CD, Roberts RJ. A comparison of the effects of temperature on wound healing in a tropical and a temperate teleost. J Fish Biol. 1975;7:173-82.

6. Schreck CB. Immunomodulation: endogenous factors. In: Iwama G, Nakanishi T, editors. The fish immune system: organisms, pathogen, and environment. San Diego: Academic Press; 1996. p. 311-38.

7. Walsh MG, Bjorgo KA, Isely JJ. Effects of Implantation method and temperature on mortality and loss of simulated transmitters in hybrid striped bass. Trans Am Fish Soc. 2000;129:539-44.

8. Mueller RP, Moursund RA, Bleich MD. Tagging juvenile Pacific lamprey with passive integrated transponders: methodology, short-term mortality, and influence on swimming performance. N Am J Fish. Manag. 2006;26:361-6.

9. Knight BC, Lasee BA. Effects of implanted transmitters on adult bluegills at two temperatures. Trans Am Fish Soc. 1996;125:440-9.

10. Yasuda T, Yukami R, Ohshimo S. Fishing ground hotspots reveal long-term variations in chub mackerel Scomber japonicus habitat in the East China Sea. Mar Ecol Prog Ser. 2014;501:239-50.

11. Kleinbaum DG, Klein M. Survival analysis: a self-learning text. New York: Springer; 1996.

12. Ammann AJ, Michel CJ, MacFarlane RB. The effects of surgically implanted acoustic transmitters on laboratory growth, survival and tag retention in hatchery yearling Chinook salmon. Environ Biol Fish. 2013;96:135-43.

13. Brown RS, Geist DR, Deters KA, Grasell A. Effects of surgically implanted acoustic transmitters $>2 \%$ of body mass on the swimming performance, survival and growth of juvenile sockeye and Chinook salmon. J Fish Biol. 2006;69:1626-38.

14. Frost DA, McComas RL, Sandford BP. The effects of a surgically implanted microacoustic tag on growth and survival in subyearling fall Chinook Salmon. Trans Am Fish Soc. 2010;139:1192-7.

15. Bunnell DB, Isely J. Influence of temperature on mortality and retention of simulated transmitter in rainbow trout. N Am J Fish. Manag. 1999;19:152-4.

16. Schaefer KM. Lethal temperature and the effect of temperature change on volitional swimming speeds of chub mackerel, Scomber japonicus. Copeia. 1986;1986:39-44.

17. Ishibashi R, Murata O, Yamamoto S, Oka Y, Yoneshima H, Kato K, Miyashita S, Kumai H. Growth and Gonad Development of captive chub mackerel Scomber japonicus (Perciformes: Scombridae). Aqua Sci. 2006;54:195-200.

18. Wedemeyer $\mathrm{G}$. The role of stress in disease resistance of fishes. In: Snieszko SF, editor. A symposium on disease in fishes and shellfishes. Washington: American Fisheries Society; 1970. p. 30-5.

19. Snieszko SF. The effects of environmental stress on outbreaks of infectious diseases of fishes. J Fish Biol. 1974;6:197-208.

20. Jepsen N, Davis LE, Schreck CB, Siddens B. The physiological response of chinook salmon smolts to two methods of radiotagging. Trans Am Fish Soc. 2001;130:495-500.

21. Lower N, Moore A, Scott AP, Ellis T, James JD, Russell IC. A non-invasive method to assess the impact of electronic tag insertion on stress levels in fish. J Fish Biol. 2005;67:1202-12.

22. Caputo M, O'Connor CM, Hasler CT, Hanson KC, Cooke SJ. Long-term effects of surgically implanted telemetry tags on the nutritional physiology and condition of wild freshwater fish. Dis Aquat Org. 2009;84:35-41.

23. Ohkawa $\mathrm{H}$. Tagging experiments on the commercial pelagic fishes in the East China Sea and its adjacent area of the Japan Sea-I. Common mackerel, Scomber japonicus. Bull Seikai Nat Fish Res Inst. 1976;47:15-47.

24. Økland F, Hay CJ, Næsje TF, Nickandor M, Thorstad EB. Learning from unsuccessful radio tagging of common carp in a Namibian reservoir. J Fish Biol. 2003;62:735-9.

25. Makiguchi $Y$, Ueda H. Effects of external and surgically implanted dummy radio transmitters on mortality, swimming performance and 
physiological status of juvenile masu salmon Oncorhynchus masou. J Fish Biol. 2009;74:304-11.

26. Shiraishi T, Ketkar SD, Katoh Y, Nyuji M, Yamaguchi A, Matsuyama M. Spawning frequency of the Tsushima Current subpopulation of chub mackerel Scomber japonicus off Kyushu, Japan. Fish Sci. 2009;75:649-55.

27. Mitsunaga Y, Arai N, Sakamoto W. Long term recording of red sea bream behaviour using a temperature and depth data logger. J Adv Mar Sci Tech Soc. 2002;8:11-25.
28. Tanaka H, Naito Y, Davis NDZ, Urawa S, Ueda H, Fukuwaka M. First record of the at-sea swimming speed of a Pacific salmon during its oceanic migration. Mar Ecol Prog Ser. 2005;291:307-12.

29. Yasuda T, Katsumata H, Kawabe R, Nakatsuka N, Kurita Y. Identifying spawning events of Japanese flounder Paralichthys olivaceus from depth time-series data. J Sea Res. 2013;75:33-40.

Submit your next manuscript to BioMed Central and take full advantage of:

- Convenient online submission

- Thorough peer review

- No space constraints or color figure charges

- Immediate publication on acceptance

- Inclusion in PubMed, CAS, Scopus and Google Scholar

- Research which is freely available for redistribution

Submit your manuscript at www.biomedcentral.com/submit 